\title{
Magnetic Viscosity for Cyclostratigraphic Logging of Argillaceous Sediment
}

\author{
by Julien Thiesson, Emilia Huret, Alain Tabbagh, and Bruno Galbrun
}

doi:10.2204/iodp.sd.8.02.2009

\section{Introduction}

Magnetic susceptibility (MS) is currently used as a directly representative proxy for the study of climatic variations, and for cyclostratigraphic studies. It depends on the concentration of magnetic minerals in the rocks, but does not allow identifying the magnetic minerals. In the case of argillaceous sediments, the paramagnetism of clay particles often plays a major role in determining the magnitude of their magnetic susceptibility, while the presence of ferrimagnetic iron oxides or sulfides cannot be assessed using susceptibility measurements alone. Among the different methods that can be used to detect ferrimagnetic particles magnetic viscosity (MV) characterizing the delay corresponding to the acquisition or loss of induced magnetization, has the same advantages as MS. Its measurement is direct, rapid and has been proven to be very efficient in detecting the presence of secondary ferrimagnetic minerals in soils. A MV measurement technique was tested on cores taken from a borehole, in Callovian-Oxfordian formations in the eastern Paris Basin (France) (Fig. 1). Although the MV values are very small, they have cyclic variations of which strongest values are found at the base of the Lower Oxfordian. These values, when correlated to MS, Gamma Ray (GR) and a sequential interpretation of a borehole drilled close-by are found to be associated with the

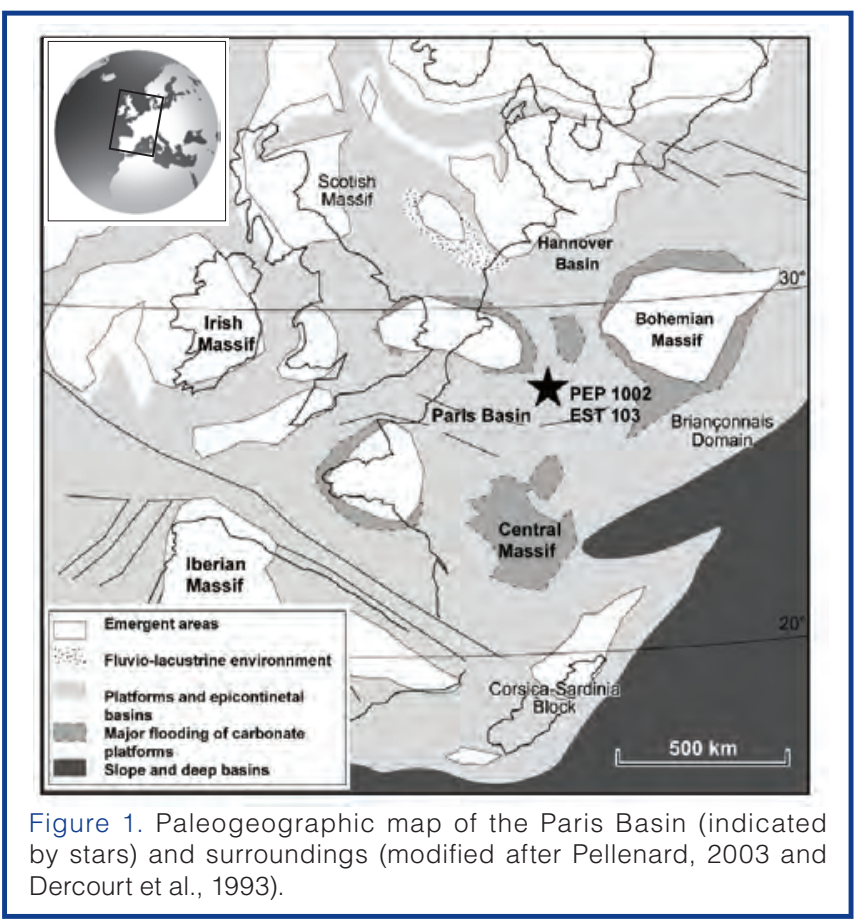

maximum clay fraction in the core samples, a MS maximum, and a major transgression event. Consequently, a significant increase in ferrimagnetic minerals can be associated with this event.

Spectral analysis of the high resolution MV and MV/MS records reveals dominant patterns, identified as $95 \mathrm{ky}$ eccentricity cycles, identical to those found using MS and GR analysis. Magnetic viscosity, which is sensitive to specific ferrimagnetic grains, thus appears to be a well suited proxy for cyclostratigraphic analysis, adapted to the Mesozoic homogeneous argillaceous series. Its sensitivity is complementary to, and extends the abilities of, magnetic susceptibility.

Cyclostratigraphy constitutes a remarkable tool to estimate the duration of sedimentary sequences. The method depends on the existence of climatic proxy records, whose high-resolution acquisition enables temporal resolutions to the scale of Milankovitch cycles (i.e., eccentricity, obliquity, and precession cycles with durations of $405 \mathrm{ky}, 95 \mathrm{ky}, 40 \mathrm{ky}$, $20 \mathrm{ky}$, and $18 \mathrm{ky}$ ). The quality of the records is often sufficient to allow the cyclostratigraphic series to be correlated with theoretical astronomical forcing over the past 40-60 My (Laskar et al., 2004). In such studies, magnetic properties-in particular the magnetic susceptibility (MS) - are powerful tools for cyclostratigraphic analysis (Crick et al., 2000; Latta et al., 2006). The properties, concentration, and grain size of the magnetic minerals are affected by erosion, transport, sedimentation, and/or diagenesis. MS fluctuations in a sedimentary sequence can thus reflect paleoclimatic variations and provide a record of orbital cycles. This technique has been frequently used in recent cyclostratigraphic studies; it is also a very promising diagnostic tool for the analysis of Mesozoic series (Weedon et al., 1999; Huret, 2006; Boulila et al., 2008a, 2008b). MS can be measured at low cost with a very high resolution on core samples, or by downhole logging with a high sampling rate, of the order of one centimeter. The measurements can be made in a few seconds on core, and they are simple to implement and non-destructive. The MS in argillaceous sediments is generally dominated by paramagnetic minerals, although a significant fraction of ferrimagnetic iron oxide or iron sulfide grains may also contribute. In question is however whether the ferrimagnetic fraction is more sensitive to climate changes, and thus more reliable in cyclostratigraphic studies. 
It is possible to determine the presence of ferrimagnetic grains by computing the remanent magnetization, if the total field and the MS logging analysis are combined (Desvignes et al., 1992), either by measuring the magnetic viscosity (MV). Our aim was to assess the use of MV in mineralogical and sedimentological change interpretations. We tested the method on samples from the PEP 1002 borehole (Andra Underground Laboratory, France) and compared the observed MV variations with those determined using MS and sedimentology.

\section{Magnetic Viscosity}

When an external magnetic field is applied to a material, it acquires an induced magnetization with a delay which can be measured. In the case of an AC-applied field, this delayed reaction is described by a complex susceptibility: $\kappa=\kappa_{p h}-i \kappa_{q}$ in the frequency domain. In the time domain, for an applied step impulse function, this delay corresponds either to an increase in magnetization after the applied field has been switched on, or to a decrease in magnetization after it has been switched off. Magnetic viscosity has been observed experimentally for a wide variety of rocks, from soils (Mullins and Tite, 1973) to oceanic basalts (Trigui and Tabbagh, 1990). Theoretical approaches (Néel, 1949, 1950; Mullins and Tite, 1973) have established that for single domain grains and for wall displacement induced by thermal fluctuations in massive multi-domain grains, a quantitative relationship exists between the quadrature susceptibility ( $\kappa_{\mathrm{qu}}$, where $\omega$ is the angular frequency and $\kappa_{t d}$ is the time domain susceptibility) the decrease of in-phase susceptibility as a function of frequency, and time domain susceptibility variations:

$$
\frac{2}{\pi} \kappa_{q u}=-\frac{\partial \kappa_{p h}}{\partial \ln \omega}=\frac{\partial \kappa_{t d}}{\partial \ln t}
$$

This relationship has been experimentally verified (Bloemendal et al., 1985; Dabas et al., 1992) in the presence of hyperfine grains. The role of hyperfine grains, at the transition between the superparamagnetic (SP) and stable single domain (SSD) states, has been confirmed (Dearing et al., 1996; Worm, 1998) and has been demonstrated to be very significant in soils with grain sizes below $30 \mathrm{~nm}$ as an indicator of the presence of secondary ferrimagnetic minerals (SFM).

In sediments, the MS corresponds to the sum of the contributions from paramagnetic and ferrimagnetic minerals, while the MV is affected only by single domain hyperfine grains. Therefore, the ratio MV/MS can be used to normalize with respect to the total magnetic particle content.

\section{Geological Context at the Studied Boreholes}

The studied boreholes truncate the Callovian-Oxfordian formation of the eastern Paris Basin (Fig. 1). They comprised homogeneous argillaceous series (around $130 \mathrm{~m}$ thick) deposited in a marine shelf environment. This formation is included in a second-order transgressive/regressive cycle (Hardenbol et al., 1998), with a maximum flooding surface situated near the base of the Oxfordian stage in the Mariae zone (Pellenard et al., 1999; Pellenard, 2003; Ferry et al., 2007). MS studies of many boreholes at the Bure site show that this evolution reflects the major transgressive/ regressive changes of second and third orders, in which the transgressive phase is represented by an increase in MS and the regressive phase corresponds to a decrease in MS (Huret, 2006).

The rocks consist of approximately $50 \%$ clay minerals, $25 \%$ silt (quartz, feldspar, muscovite), and $25 \%$ carbonate (calcite and dolomite) whereas micas and pyrite are minor constituents $(<5 \%)$. The MS is influenced mainly by the paramagnetic clay minerals and partly by ferrimagnetic minerals; significant concentrations are situated at the Callovian-Oxfordian boundary and in a clay maximum at the base of the lower Oxfordian (Esteban et al., 2006).

Two data sets from boreholes in this stratigraphy were used. The PEP 1002 borehole in the Callovian-Oxfordian argillaceous formation was accessed via the floor of the Bure Underground Laboratory at the depth of $490-\mathrm{m}$. This 19-m-long borehole is vertical. The studied interval covers approximately the top of the upper Callovian and the base of the lower Oxfordian (Fig. 2). The EST 103 hole was drilled on the Bure site, at a distance of approximately $200 \mathrm{~m}$ from the PEP 1002 borehole. The time interval of the EST 103 borehole could be defined as ranging from the top of the upper Callovian to the base of the lower Oxfordian (Thierry et al., 2006), by evaluating ammonite deposits. The clay content, GR value, and MS value maxima occur at depths of approximately $500 \mathrm{~m}$ in the EST 103 borehole and $490+3 \mathrm{~m}$ in PEP 1002. This corresponds to the maximum flooding surface (MFS).

\section{Measurements and Data Processing}

When the MS2B (Bartington Ltd) dual-frequency instrument was used, no difference was observed between the in-phase magnetic susceptibilities at $0.465 \mathrm{kHz}$ and $4.65 \mathrm{kHz}$. This means that the quadrature susceptibility is smaller than $6.8 \times 10^{-7}$ S.I. (for frequency dependent susceptibility of $1 \%$, and a low frequency susceptibility of $10^{-4}$ S.I.). Thus, we chose the more sensitive time-domain electromagnetic technique (TDEM). A 0.084-m-diameter coincident loop sensor was built in order to be able to surround the core. Measurements were performed with TS6 electronics (Protovale Oxford Ltd), with a 2-cm sampling interval. The data were digitally recorded with thirty values stacked at each measurement point. To correct for thermal and electronic drifts, we took zeroing calibrations at regular intervals. 


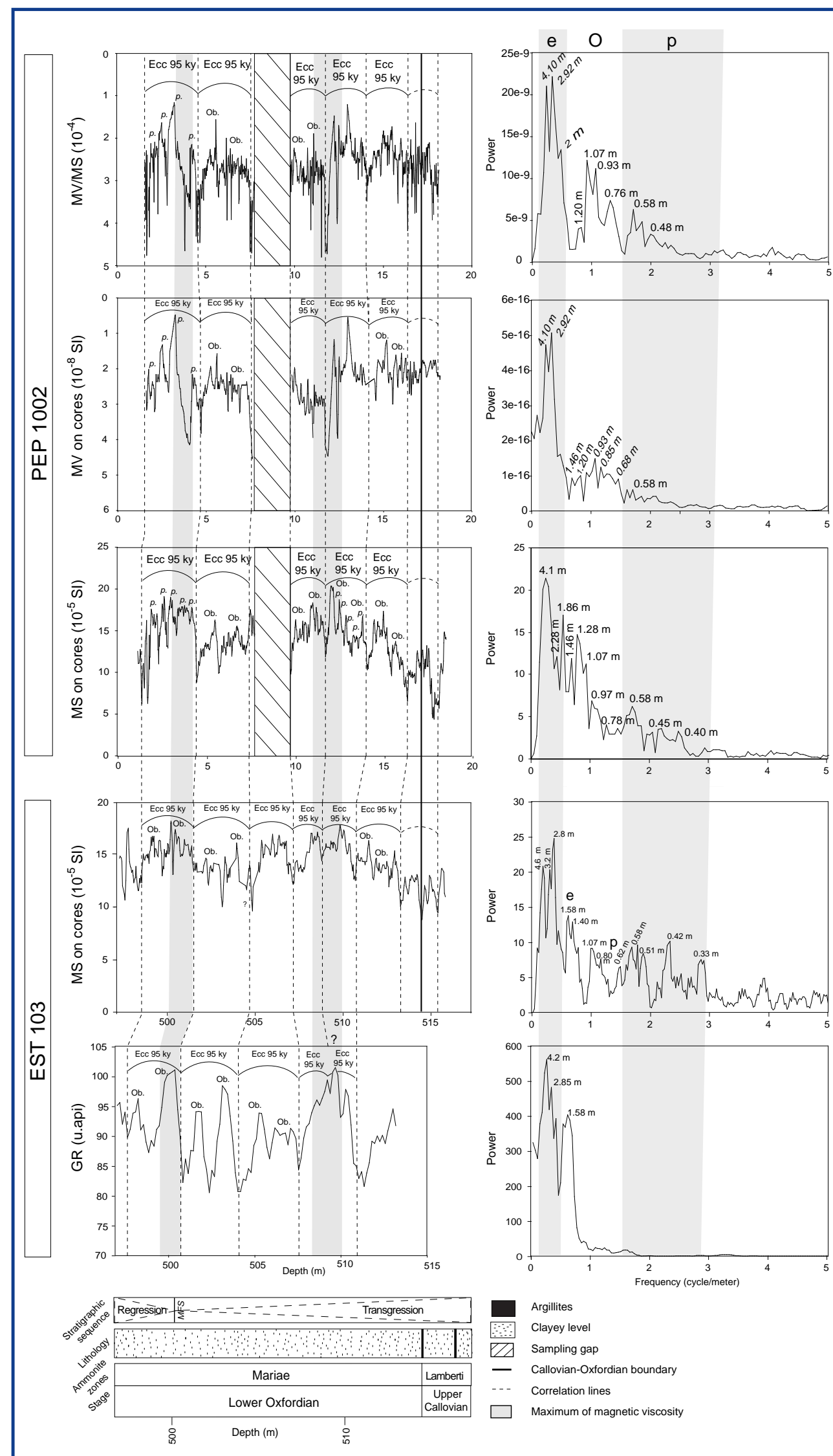

Figure 2. Biostratigraphy (Thierry et al., 2006), lithology (Huret, 2006), sequence stratigraphy interpretation and analysis of Gamma Ray (GR) well logging, and Magnetic Susceptibility (MS), Magnetic Viscosity (MV) and MV/MS ratio of the EST 103 and PEP 1002 boreholes. The light grey bands indicate zones with the strongest MV values. Presentation of $2 \pi-M T M$ power spectrum after trend rejection. Identification of orbital cycles in the recordings (3 point smoothing of the MS and MV curves), symbols: eccentricity 95 ky (e), obliquity $(O)$ and precession (p).
As the core is not continuous and presents some fractures and gaps, the data had to be corrected for these effects. The signal decay was computed as a function of core length, using an abacus, for several gap sizes. The final data reduction step involved transforming the measured voltage into apparent quadrature susceptibility, after calibrating the global loop and instrument response using a small 5-mm-diameter metallic sphere (Tabbagh and Dabas, 1996). In order to provide a good fit for the experimental values, the total instrument sensitivity was increased so that its total dynamic range corresponded to $10^{-7}$ S.I., in good agreement with the absence of a measurable frequency dependence of the MS2B instrument.

\section{Magnetic Viscosity Results}

The MV $\log$ is presented in Fig. 2, together with the MS (2-cm sampling interval), the $\mathrm{MV} / \mathrm{MS}$ ratio recordings, and the GR (10-cm sampling interval) and the MS (4-cm sampling interval) recordings from the EST 103 borehole. These recordings are correlated with the biostratigraphic data. The values of MV we obtained are very low (<5 $\times 10^{-8}$ S.I.), which is roughly 100 times lower than in soils (Thiesson et al., 2007). This result can be explained by the very small secondary ferrimagnetic mineral content (possibly due to $\mathrm{Fe}^{++}$ions dissolved in water during deposition and compaction).

The long-term evolution and high-frequency variations of the MS are similar between the EST 103 and PEP1002 boreholes. The MS maxima in the PEP 1002 hole are located at depths ranging from $3 \mathrm{~m}$ to $5 \mathrm{~m}$, and 
those between $10 \mathrm{~m}$ and $13 \mathrm{~m}$ are correlated with strong GR values characterizing clay-rich zones. Moreover, the GR log presents the same high frequency variations as the MS recording (Fig. 2). These similarities confirm that the presence of paramagnetic clay minerals is the dominant contributor to MS. Correlations between MV and MS are less evident, although they present the same cyclic variations (of the order of $3 \mathrm{~m}$ in thickness). They appear to be anti-correlated, rather than correlated; nevertheless, the strongest MV values, which occur at $3.5 \mathrm{~m}, 7.5 \mathrm{~m}$, and 11-13 m, correspond to maxima of both MS (values varying, 15-20 x 10-5 SI) and GR (Fig. 2). It should be noted that the relative variations in $\mathrm{MV}$ (variations divided by the mean value) are clearly higher than those in MS.

The main discrepancy, together with the main high and medium frequency variations observed in the MV, lies between $3 \mathrm{~m}$ and $4 \mathrm{~m}$. This is associated with a strong relative increase in $\mathrm{MV}$, followed by a strong relative decrease. By comparison, the sedimentology and stratigraphical information corresponds to a MS maximum and, after comparison with the EST103 borehole, is found to be correlated with the position of the second-order maximum flooding surface (MFS) known to exist at the base of the Lower Oxfordian. This level also corresponds to a clay-rich maximum in the EST 103 borehole, with strong GR values. A second interval with strong MV, MS, and GR values is observed between the depths of $11 \mathrm{~m}$ and $13 \mathrm{~m}$, but is not associated with a particular lithological or stratigraphical change. However, the base of the Mariae zone can be recognized as the most argillaceous level of the series (Pellenard et al., 1999; Esteban et al., 2006).

The highest MS values, found at $3 \mathrm{~m}$ depth in the PEP 1002 borehole, indicate that the MFS may correspond to (i) a greater quantity of paramagnetic clay particles, or (ii) a greater quantity of magnetite grains of terrigenic origin (Esteban et al., 2006), or (iii) greater in situ generation of biogenic minerals (greigite or magnetite). The strong changes in MV suggest that the processes involved are even more complex than suggested by MS alone; inside this period of high susceptibility, rapid and strong changes occurred in the sediment transfer modes, and possibly in the oxygen content of water. In the absence of a detailed mineral analysis, it is not possible to determine exactly what happened during the flood event.

We would like to emphasize that, for the MFS event recorded at 3-4 $\mathrm{m}$, the $\mathrm{MV} / \mathrm{MS}$ ratio provides a large quantity of useful information. It not only highlights changes that have already been observed using GR or MS, as for the case just above $11 \mathrm{~m}$, but also reveals more complex, detailed variations which have yet to be understood. As the relative variations in MS are of limited extent (20\% maximum) and are correlated with clay content, the MV/MS ratio can be initially interpreted as expressing the small ferrimagnetic particle content of the clay. Variations in this ratio could thus provide an indication of the sediment's origin.

\section{Frequency Content}

MV data exhibited a higher relative variability than that recorded using MS (or GR). However, in order to assess its relevance for cyclostratigraphic studies, the frequency content of the relevant recordings must also be analyzed.

Time series analysis of the PEP 1002 and EST 103 well logs and core data were carried out using the "Multi-Taper Method" (Thomson, 1982, 1990). This method, which we implemented with Matlab ${ }^{\circledR}$ software, estimates the power spectral density of a time series through the application of a set of orthogonal tapers, while maintaining suitable confidence levels. In spite of the presence of some gaps in the PEP 1002 data and of the limited length of the recordings, our analyses were performed over the full series. The data was re-sampled every $2 \mathrm{~cm}$, using linear interpolations (except for the GR, which has a constant sampling step), and the linear trend was removed. The results are shown in Fig. 2, for which the data was smoothed (3-point average) to improve the contrast of the high frequency variations.

Identification of the orbital cycles was achieved using the frequency ratio method (Mayer and Appel, 1999), which consists of comparing the frequency ratio of pairs of dominant cycles observed in the series, with those known to characterize the Earth's orbital cycles (i.e., $18.2 \mathrm{ky}$ and $21.9 \mathrm{ky}$ for precession, $37.7 \mathrm{ky}$ for obliquity, and $95 \mathrm{ky}$ for eccentricity) during the Jurassic period (Berger and Loutre, 1994). GR analysis of the EST 103 reveals a power spectrum with only two major peaks, with periods of $2.85 \mathrm{~m}$ and $4.2 \mathrm{~m}$, and a weaker peak at $1.58 \mathrm{~m}$, visible on the curve (Fig. 2). This power spectrum does not have small high-frequency variations similar to those associated with the MS data, because a longer $(10 \mathrm{~cm})$ sampling step was used. The MS spectrum of the EST 103 hole presents several peaks with strong amplitudes, the first identical in frequency to those of the GR spectrum, with periods between $4.6 \mathrm{~m}$ and $2.8 \mathrm{~m}$ clearly visible (Fig. 2). Others periods, close to $1.4 \mathrm{~m}$ and $1.58 \mathrm{~m}, 1.07 \mathrm{~m}$ and $0.8 \mathrm{~m}$, and $0.62 \mathrm{~m}$ and $0.33 \mathrm{~m}$, are also characterized by comparatively strong amplitudes. By comparing the terrestrial orbital frequency ratios with those derived from the GR and MS recordings at the EST 103 hole (Table 1), we can associate the core cycles (with periods of 2.8-4.1 m) with 95-ky eccentricity cycles. The core cycles with periods of $1.58-0.62 \mathrm{~m}$ can be associated with obliquity cycles, and the core cycles with periods $0.33-0.80 \mathrm{~m}$ can be associated with precession cycles. These periodicity allocations agree with the cyclostratigraphic analysis performed on cores of another hole (EST 322) drilled $10 \mathrm{~km}$ from EST103 and PEP 1002 (Boulila et al., 2008b). The fact that the observed cycles are spread over a large range of frequencies can be explained by variations in the rate of 
sedimentation. The sedimentation rate, in the MS recordings associated with 95-ky eccentricity cycles, increases from that corresponding to the $2.8-3.2 \mathrm{~m}$ thicknesses at the bottom of the recording, to that resulting in a thickness of approxi-mately $4 \mathrm{~m}$ at the top (Fig. 2).

The spectral analysis of MS in PEP 1002 is more complex. Eccentricity cycles are expressed, as for the EST 103 borehole, by a $4.1-\mathrm{m}$ thickness. However, other cycles such as obliquity and precession are more difficult to identify because the spectrum contains many close frequency peaks with strong amplitudes. This effect is certainly amplified by the presence of a core sample gap (7.76-9.26 m). Similar spectral characteristics have already been observed by Weedon (1989); however, the frequency ratio of the major peaks allowed Milankovitch cycles to be identified with frequencies in agreement with those found at the EST 103 borehole (Table 1). MS stratigraphic correlations between the two boreholes show similar trends and clearly present the same high-frequency cycles. In this correlation, some thickness variations are also expressed by small differences in MS measurements.

The MV spectrum for PEP 1002 in Fig. 2 is clearer than that produced from the MS recordings. It has the same two strong peaks corresponding to periods of $2.92 \mathrm{~m}$ and $4.1 \mathrm{~m}$, associated with the 95-ky eccentricity cycles. Although the higher frequency cycles are not very strong, the use of frequency ratios enabled obliquity and precession cycles to be identified. The spectrum of the MV/MS ratio is the most representative of all the spectra, with all Milankovitch cycles expressed with strong, distinct amplitude peaks. The MV and MV/MS curves (inversed in Fig. 2) clearly show the eccentricity cycles corresponding to thickness periods in the range of $2 \mathrm{~m}$ to $4 \mathrm{~m}$.

\section{Conclusions}

The results presented in this paper are the first on direct magnetic viscosity measurements of argillite samples. Measurements of PEP1002 cores are shown to be informative, and they demonstrate that MV measured by the TDEM technique appears to be a potentially promising climate proxy for high-resolution cyclostratigraphic studies. The resolution and lateral sensitivity of MV measurements should be similar to that of MS and could be adjusted by appropriate definition of the coil geometry. The potential of MV as a proxy for stratigraphic climate analysis is its ability to constrain the ferromagnetic iron oxide or sulfide grain fractions. This capability potentially can be used to improve the identification of sedimentary sources, changes in mineralogy which occurs during transport, and sedimentation process. It is now necessary to determine precisely the advantages and drawbacks of this type of measurement and the extent to which it can be complementary to MS and other petrophysical analyses. The construction of a MV wire-logging tool could take advantage of the experience acquired in surface prospecting instruments.

\section{Acknowledgements}

We wish to thank Patrick Landais, Alain Trouiller, and Hervé Rebours of the ANDRA (French Agence Nationale pour la gestion des Déchets Radioactifs) for authorizing and assisting with the measurement of the PEP1002 cores at the Bure site. We are grateful to Linda Hinnov for fruitful discussions and to Slah Boulila for the preparation of the illustrations provided in this paper.

\section{References}

Berger, A., and Loutre, M.F., 1994. Astronomical forcing through geological time. In de Boer, P.L, and Smith, D.G. (Eds.), Orbital Forcing and Cyclic Sequences,. Int. Ass. Sed. Sp. Pub., 19:15-24.

Bloemendal, J., Barton, C.E., and Radhakrishnamurty, C., 1985. Correlation between Rayleigh loops and frequency-dependent and quadrature susceptibility: application to magnetic granulometry of rocks. J. Geophys. Res., 90:8759-8792, doi:10.1029/JB090iB10p08789.

Boulila, S., Galbrun, B., Hinnov, L.A., and Collin, P.Y., 2008 a. High-resolution cyclostratigraphic analysis from magnetic susceptibility in a Lower Kimmeridgian (Upper Jurassic) marl-limestone succession (La Méouge, Vocontian Basin, France). Sed. Geol., 203:54-63, doi:10.1016/j.sedgeo. 2007.10.004.

Boulila, S., Hinnov, L.A., Huret, E., Collin, P.Y., Galbrun B., Fortwengler, D., Marchand, D., and Thierry, J., 2008b. Astronomical calibration of the Early Oxforiden (Vocontian and Paris basins, France): consequences of revising the Late Jurassic time scale. Earth Planet. Sci. Lett., 276:40-51, 
doi:10.1016/j.epsl.2008.09.006.

Crick, R.E., Ellwood, B.B., El Hassani, A., and Feist, R., 2000. Proposed magnetostratigraphy susceptibility magnetostratotype for the Eifelian-Givetian GSSP (Anti-Atlas, Morocco). Episodes, 23:93-101.

Dabas, M., Jolivet, A., and Tabbagh, A., 1992. Magnetic susceptibility and viscosity of soils in a weak time varying field. Geophys J. Int., 108:101-109, doi:10.1111/j.1365-246X.1992.tb00841.x.

Dearing, J.A., Dann, R.J.L., Hay, K., Lees, J.A., Loveland, P.J., Maher, B.A., and O'Grady, K., 1996. Frequency-dependent susceptibility measurements of environmental materials. Geophys. J. Int., 124:228-240, doi:10.1111/j.1365-246X.1996. tb06366.x.

Dercourt, J., Ricou, L.E., and Vrielynck, B., 1993. Atlas Tethys palaeoenvironmental maps. Paris, (Gauthier-Villars), 307pp.

Desvignes, G., Barthès, V., and Tabbagh, A., 1992. Direct determination of natural remanent magnetization effect in a hole drilled in layered ground from magnetic field and susceptibility logs. Geophysics, 57:872-884, doi:10.1190/1.1443300.

Esteban, L., Bouchez, J.L., and Trouiller, A., 2006. The CallovoOxfordian argillites from Eastern Paris basin: magnetic data and petrofabrics. C. R. Geoscience, 338:867-881.

Ferry, S., Pellenard, P., Collin, P.Y., Thierry, J., Marchand, D., Deconinck, J.F., Robin, C., Carpentier, C., Durlet, C., and Curial, A., 2007. Synthèse des données stratigraphiques récentes sur les formations bathoniennes à oxfordiennes de l'Est du Bassin de Paris. Mém. Soc. Géol. Fr., 178:37-52.

Hardenbol, J., Thierry, J., Farley, M.B., Jacquin, T., de Graciansky, P.C., and Vail, P.R., 1998. Mesozoic and Cenozoic sequence chronostratigraphic framework of European basins. In de Graciansky, P.-C., Hardenbol, J., Jacquin, T., and Vail, P.R. (Eds.), Mesozoic and Cenozoic Sequence Stratigraphy of European Basins, Spec. Publ. SEPM 60, Tulsa, Okla., U.S.A. (SEPM Society for Sedimentary Geology), 3-13.

Huret, E., 2006. Analyse cyclostratigraphique des variations de la susceptibilité magnétique des argilites callovo-oxfordiennes de l'Est du Bassin de Paris: application à la recherche de hiatus sédimentaires. $\mathrm{PhD}$ thesis, Université Pierre et Marie Curie, Paris, France.

Laskar, J., Robutel, P., Joutel, F., Gastineau, M., Correia, A.C.M., and Levrard, B., 2004. A long-term numerical solution for the insolution quantities of the Earth. Astron. Astrophys., 428:261-285, doi:10.1051/0004-6361:20041335.

Latta, D.K., Anastasio, D.J., Hinnov, L.A., Elrick, M., and Kodama, K.P., 2006. Magnetic record of Milankovitch rhythms in lithologically noncyclic marine carbonates. Geology, 34:29-32, doi:10.1130/G21918.1.

Mayer, H., and Appel, E., 1999. Milankovitch cyclicity and rock-magnetic signatures of paleoclimatic changes in the early Cretaceous Biancone Formation of the Southern Alps, Italy. Cret. Res., 20:189-214, doi:10.1006/cres.1999.0145.

Mullins, C.E., and Tite, M.S., 1973. Magnetic viscosity, quadrature susceptibility and frequency dependence of susceptibility in single domain assemblies of magnetite and maghemite. J. Geophys. Res., 78:804-809, doi:10.1029/JB078i005p00804.

Néel, L., 1949. Théorie du traînage magnétique des ferromagnétiques en grains fins avec application aux terres cuites. Annales Géophysique, 5:99-136.

Néel, L., 1950. Théorie du traînage magnétique des substances mas- sives dans le domaine de Rayleigh. Le Journal de Physique et le Radium, 11:49-61.

Pellenard, P., 2003. Message terrigène et influences volcaniques au Callovien-Oxfordien dans les bassins de Paris et du SudEst de la France. Soc. Géol. Nord, Publ. 31, 362pp.

Pellenard, P., Deconinck, J.F., Marchand, D., Thierry, J., Fortwengler, D., and Vigneron, G., 1999. Contrôle géodynamique de la sédimentation argileuse du Callovien-Oxfordien moyen dans l'Est du bassin de Paris : influence eustatique et volcanique. C. R. Acad. Sci. Paris, 328:807-813.

Tabbagh, A., and Dabas, M., 1996. Absolute magnetic viscosity determination using time domain electromagnetic devices. Archaeol. Prospect, 3:92-100.

Thierry, J., Marchand, D., Fortwengler, D., Bonnot, A., and Jardat, R., 2006. Les ammonites du Callovien-Oxfordien des sondages Andra dans l'Est du Bassin de Paris: bio-chronostratigraphie, intérêts paléoécologique et paléogéographique. $C$. $R$. Geoscience, 338:834-853, doi:10.1016/j.crte.2006.05.005.

Thiesson, J., Tabbagh, A., and Flageul, S., 2007. TDEM magnetic viscosity prospecting using a Slingram coil configuration. Near Surface Geophysics, 5(6):363-374.

Thomson, D.J., 1982. Spectrum estimation and harmonic analysis. Proc. IEEE, 70:1055-1096, doi:10.1109/PROC.1982.12433.

Thomson, D.J., 1990. Time series analysis of Holocene climate data. Phil. Trans. R. Soc. Lond., 330:601-616.

Trigui, M., and Tabbagh, A., 1990. Magnetic susceptibilities of oceanic basalts in alternative fields. J. Geomag. Geoelect., 42:621-636.

Weedon, G P., 1989. The detection and illustration of regular sedimentary cycles using Walsh power spectra and filtering, with examples from the Lias of Switzerland. J. Geol. Soc. Lond., 146:133-144, doi:10.1144/gsjgs.146.1.0133.

Weedon, G.P., Jenkyns, H.C., Coe, A.L., and Hesselbo, S.P., 1999. Astronomical calibration of the Jurassic time scale from cyclostratigraphy in British mudrock formations. Phil. Trans. Royal Soc. Lond., 357:1787-1813, doi:10.1098/ rsta.1999.0401.

Worm, H.U., 1998. On the superparamagnetic stable single domain transition for magnetite and frequency dependent susceptibility. Geophys. J. Int., 133:201-206, doi:10.1046/j. 1365-246X.1998.1331468.x.

\section{Authors}

Julien Thiesson, Université Pierre et Marie Curie, UMR 7619, Sisyphe, case 105, 4 place Jussieu, 75252 Paris cedex 05, France and INRA, Centre de Recherche d'Orléans, UR 0272 Science du Sol, 2163 Avenue de la Pomme de Pin, CS 40001 ARDON, 45075 ORLEANS Cedex 2, France, e-mail : julien.thiesson@upmc.fr.

Emilia Huret, Andra, 1/7 rue Jean Monnet, Parc de la croix blanche, 92298 Châtenay Malabry cedex, France, e-mail: emilia.huret@andra.fr.

Alain Tabbagh, Université Pierre et Marie Curie, UMR 7619, Sisyphe, case 105, 4 place Jussieu, 75252 Paris cedex 05, France, e-mail: alain.tabbagh@upmc.fr.

Bruno Galbrun, Université Pierre et Marie Curie, ISTeP, case 117, 4 place Jussieu, 75252 Paris cedex 05, France, e-mail: bruno.galbrun@upmc.fr. 